areas. In particular, there is a strong bias towards London in the proportion of the population classified as deprived. The index fails to recognise the nature of deprivation in the north of England, and, utilising Jarman's index, any resource allocation exercise would benefit the Thames regions at the expense of peripheral regions. Also, the Jarman index has been used outside its original domain of application-namely, that of general practitioners' workload - to guide the allocation of both health care and other resources. This raises the issue of how a statistical index develops a life of its own.

I thank Doug Anderson and Bill Wood of Doncaster College for their comments on an earlier draft of this paper and Roy Carr-Hill and Trevor Sheldon for comments on a later draft.

1 Secretaries of State for Health, Wales, Northern Ireland, and Scotland. Working for patients. London: HMSO, 1989. (Cmnd 555 .)

2 Acheson D. Primary health care in inner London. London: Department of Health and Social Security, 1981. (Report of a study group commissioned by the London Health Planning Consortium

Jarman B. Identification of underprivileged areas. BMF 1983;286:1705-9.

4 Jarman B. Underprivileged areas: validation and distribution of scores. $B M \mathcal{F}$ 984;289:1587-92.

Irving D, Rice P. Information for health services planning from the 1981 census 84/11. London: Kings Fund, 1984

6 Secretaries of State for Social Services, Wales, Northern Ireland, and Scotland. Promoting better health. London: HMSO, 1987. (Cmnd 249.)

7 Department of Health. General practice in the National Health Service: the 1990 contract. London: HMSO, 1989.

8 Department of Health. Deprived areas: remuneration for GMPs. London: DoH 1990. (FPCL 46/90.
Office of Population Census and Surveys. Doncaster metropolitan borough council: small area statistics. London: HMSO, 1983.

10 Family Practitioner Services Computer Unit. Loading of deprived area status against postcode. Exeter: FPS Computer Unit, 26 February 1990.

11 Brindle D. "Deprived area" ruling cuts out extra payments for many GPs. Guardian 1990 Feb 16:2.

12 Jarman B. Underprivileged areas in the medical annual. Bristol: John Wright, 1985

13 Townsend P, Phillimore P, Beattie A. Health and deprivation: inequality and the north. London: Croom Helm, 1988

14 Townsend P, Phillimore P, Beattie A. Inequalities in health in the northern region: an interim report. Bristol: Northern Regional Health Authority, 1986. 15 Anonymous. FPC cites index bias to London. Doctor 1990 Feb 1:18

16 Thurnhurst $C$. The analysis of small area statistics and planning for health Statistician 1985;34:93-106.

17 Carr-Hill R, Sheldon T. Designing a deprivation payment for general practitioners: the UPA (8) wonderland. BMF 1991;302:393-6.

18 Whitehead M. The health divide: inequalities in health in the 1980s. London: Penguin, 1988

19 Carstairs V, Morris R. Deprivation, mortality and resource allocation. Community Med 1989:11:364-72.

20 Hutchinson A, Fry C, Sandhu B. Comparison of two scores for allocating resources to doctors in deprived areas. BMF 1989;299:1142-4.

21 Coopers and Lybrand. Integrated analysis for the review of RAWP. London: Coopers and Lybrand, 1988.

22 Hatch $S$, Sherrott $R$. Positive discrimination and the distributions of deprivations. Policy and Politics 1973;1:223-40.

23 Smith DM. The identification of problems in cities: applications of social indicators. In: Herbert DT, Smith DM, eds. Social problems and the city. Oxford: Oxford University Press, 1979:13-32

24 Church AP, Hall JM. Local initiatives for economic regeneration. In: Herbert DT, Smith DM, eds. Social problems and the city. Oxford: Oxford University Press, 1989

25 Pahl RE. Socio-political factors in resource allocation. In: Herbert DT, Smith DM, eds. Social problems and the city. Oxford: Oxford University Press, 1979

26 Collins R. Conflict sociology. New York: Academic Press, 1975.

27 Hamnett C. Area-based explanations: a critical appraisal. In: Herbert DT, Smith DM, eds. Social problems and the city. Oxford: Oxford University Press, 1979 .

(Accepted 7 fanuary 199l)
University Department of Surgery, Royal Infirmary of Edinburgh, Edinburgh EH3 9YW

$\mathrm{J} M$ Dixon, FRCS, lecturer in surgery

Medical Statistics Unit, Medical School, Edinburgh R A Elton, PHD, senior lecturer

Department of Surgery, St John's Hospital at Howden Livingston, West Lothian

J B Rainey, FRCS, consultant surgeon

D A D Macleod, FRCS, consultant surgeon

Correspondence and requests for reprints to: Mr Dixon.

BMf 1991;302:386-8

\title{
Rectal examination in patients with pain in the right lower quadrant of the abdomen
}

\author{
J M Dixon, R A Elton, J B Rainey, D A D Macleod
}

Abstract

Objective-To determine whether rectal examination provides any diagnostic information in patients admitted to hospital with pain in the right lower quadrant of the abdomen.

Design-Casualty officer or surgical registrar recorded symptoms and signs on admission on detailed forms. Final diagnosis was noted on discharge from hospital.

Setting-District general hospital.

Patients-1204 Consecutive patients admitted to hospital with pain in the right lower quadrant of the abdomen as their major complaint; 1028 had a rectal examination on admission.

Main outcome measures-Odds ratio for each symptom and sign related to final diagnosis. Results of multiple logistic regression analysis for acute appendicitis.

Results - Right sided rectal tenderness, present in 309 of those examined, was more common in patients with acute appendicitis (odds ratio $1.34, p<0.05$ ). This odds ratio was considerably less than that for other clinical signs-namely, tenderness in the right lower quadrant (odds ratio 5.09), rebound tenderness (3.34), guarding (3.07), and muscular rigidity in the abdomen (5.03). In the logistic regression analysis of patients with acute appendicitis, when allowance was made for the presence or absence of rebound tenderness, rectal tenderness on the right lost its significance. Six patients had masses palpable rectally, of which three were palpable on abdominal examination; the other three patients had acute appendicitis. No other unexpected diagnoses were established, and no useful additional diagnostic information was obtained by routine rectal examination.

Conclusion-If patients presenting with pain in the right lower quadrant of the abdomen are tested for rebound tenderness then rectal examination does not give any further diagnostic information.

\section{Introduction}

The diagnosis of the cause of pain in the right lower quadrant of the abdomen rests largely on the clinical history and results of clinical examination. Rectal examination is considered to be essential in this evaluation, ${ }^{12}$ but it is unpleasant for the patient, particularly when it is repeated by different doctors, and there is scant evidence that it provides any information of diagnostic value. ${ }^{3-5}$ We aimed to assess whether rectal examination is valuable in determining the diagnosis in patients admitted to hospital with pain in the right lower quadrant of the abdomen.

\section{Patients and methods}

We studied 1204 consecutive patients admitted to Bangour General Hospital between September 1983 and June 1989 with pain in the right lower quadrant of the abdomen as their main presenting complaint. At the time of admission a casualty officer or surgical registrar recorded on to a detailed form the patient's age, sex, and symptoms and the findings on clinical examination; these data were then entered and stored in a BBC microcomputer. Rectal examination was recorded as having been performed at admission in $1028(85 \%)$ patients, and rectal tenderness, if present, 
was assessed as right sided, left sided, or generalised. To minimise discomfort for the patient rebound tenderness was assessed principally by percussion of the abdomen rather than release of the hand after palpation. Any mass palpated rectally was recorded separately. At the time of discharge from hospital the final diagnosis was recorded on computer to complete the data file. Only those patients with histological evidence of acute inflammation in the appendix were listed as having had appendicitis.

Features in the history and findings on clinical examination were compared in different diagnostic groups by $\chi^{2}$ tests and odds ratios calculated. ${ }^{6}$ The odds ratio is a measure of the diagnostic value of a test: the higher the odds ratio the greater its diagnostic value. A multiple logistic regression analysis was also performed ${ }^{7}$ to identify those factors in the history and findings on clinical examination that were of independent significance in predicting acute appendicitis. Adjusted odds ratios for these factors were estimated from the exponentials of the logistic regression coefficients.

\section{Results}

Table I shows the final diagnoses for all 1204 patients and for the 1028 who had a rectal examination on admission. The patients' mean age was 29 (SD 18) years (range $7-87$ ). Of the total group, $37 \cdot 3 \%$ had acute appendicitis, $38 \cdot 5 \%$ non-specific abdominal pain, and $3.7 \%$ gynaecological disorders. The major differential diagnosis was therefore between acute appendicitis and non-specific abdominal pain. Although rectal examination was performed in only $85 \%$ of the total

TABLE I-Final diagnosis in all 1204 patients and numbers of patients with each diagnosis who had rectal examination

\begin{tabular}{lcc}
\hline & $\begin{array}{c}\text { No of } \\
\text { patients }\end{array}$ & $\begin{array}{c}\text { No who had } \\
\text { rectal examination }\end{array}$ \\
\hline Non-specific abdominal pain & 463 & 383 \\
Acute appendicitis & 449 & 395 \\
Renal colic & 61 & 45 \\
Gynaecological disorders & 44 & 42 \\
Intestinal obstruction & 32 & 22 \\
Urinary tract infection & 30 & 26 \\
Gall bladder disease & 12 & 12 \\
Perforated duodenal ulcer/dyspepsia & 10 & 9 \\
Diverticular disease & 6 & 5 \\
Other diagnoses & 58 & 50 \\
No diagnosis established & 39 & 39 \\
\hline Total & 1204 & 1028 \\
\hline
\end{tabular}

TABLE II - Findings on rectal examination related to final diagnosis in 1028 patients

\begin{tabular}{|c|c|c|c|c|}
\hline \multirow{2}{*}{$\begin{array}{l}\text { Finding on rectal } \\
\text { examination }\end{array}$} & \multirow{2}{*}{$\begin{array}{l}\text { No of patients } \\
\text { with sign }\end{array}$} & \multicolumn{2}{|c|}{$\begin{array}{l}\text { No (\%) with appendicitis } \\
\text { if sign: }\end{array}$} & \multirow{2}{*}{$\begin{array}{l}\text { Odds } \\
\text { ratio }\end{array}$} \\
\hline & & Absent & Present & \\
\hline Left side tender & 20 & $389(38)$ & $6(30)$ & 0.68 \\
\hline Right side tender & 309 & $261(36)$ & $134(43)$ & $1 \cdot 34^{\star}$ \\
\hline Generalised tenderness & 87 & $361(38)$ & $34(39)$ & 1.03 \\
\hline Mass felt & 6 & $392(38)$ & $3(50)$ & 1.61 \\
\hline
\end{tabular}

$\star$ Only significant difference between groups $(\mathrm{p}<0 \cdot 05)$.

TABLE III - Findings on abdominal examination related to final diagnosis in 1028 patients who had rectal examination

\begin{tabular}{|c|c|c|c|c|c|}
\hline & \multirow{2}{*}{$\begin{array}{c}\text { No of } \\
\text { patients } \\
\text { with sign }\end{array}$} & \multicolumn{2}{|c|}{$\begin{array}{l}\text { No (\%) with appendicitis } \\
\text { if sign: }\end{array}$} & \multirow{2}{*}{$\begin{array}{l}\text { Odds } \\
\text { ratio }\end{array}$} & \multirow{2}{*}{$\begin{array}{l}\text { 95\% Confidenc } \\
\text { interval }\end{array}$} \\
\hline & & Absent & Present & & \\
\hline Tenderness in right lower quadrant & 907 & $15(12)$ & $380(42)$ & $5 \cdot 09^{\star}$ & 2.98 to 9.57 \\
\hline Guarding & 537 & $123(25)$ & $272(51)$ & $3 \cdot 07^{\star}$ & 2.34 to 4.04 \\
\hline Rebound tenderness & 502 & $131(25)$ & $264(53)$ & $3 \cdot 34^{\star}$ & 2.55 to 4.40 \\
\hline Abdominal rigidity & 58 & $352(36)$ & $43(74)$ & $5 \cdot 03^{\star}$ & 2.69 to 9.88 \\
\hline
\end{tabular}

${ }^{\star} \mathrm{p}<0.001$
TABLE IV - Independent factors for predicting acute appendicitis from history and findings on clinical examination in 1028 patients who had rectal examination, as derived from multiple logistic regression

Adjusted

Coefficient SE Significance odds ratio

$\begin{array}{lllll}\text { Tenderness in right lower quadrant } & 1.67 & 0.33 & \star \star \star & 5.35\end{array}$

$\begin{array}{llll}\text { Abdominal rigidity } & 1.11 & 0.37 & \star \star\end{array} \quad 3.06$

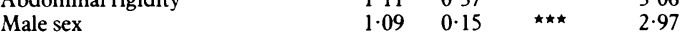

Guarding

No previous surgery

Pain of central onset

Normal micturition

Rebound tenderness

Pain aggravated by movement

Pain aggravated by coughing

$\begin{array}{ll}1 \cdot 09 & 0 \cdot 15 \\ 0.91 & 0.16 \\ 0.87 & 0.22\end{array}$

$0.87 \quad 0.22$

$\begin{array}{lll}0.73 & 0.20 \quad \star \star * \star & 2.31 \\ 0.67 & 0.16 \quad 2.03\end{array}$

$0.67 \quad 0.16 \quad \star \star \star \star-1.95$

$0.50 \quad 0.17 * \star-1.66$

0.35 0.16 *

$\begin{array}{llll}0.35 & 0.16 & \star & 1.43 \\ 0.35 & 0.17 & \star & 1.42\end{array}$

${ }^{\star} \mathrm{p}<0.05,{ }^{\star \star} \mathrm{p}<0.01,{ }^{\star \star \star} \mathrm{p}<0.001$

group, the figures were higher in the groups with acute appendicitis (88\%) and gynaecological disorders (95\%) (table I).

Rectal tenderness to the right was present in 309 of the patients examined and was more common in patients with acute appendicitis than those with other conditions $(p<0.05$, odds ratio $1 \cdot 34)$ (table II). Rectal examination yielded two findings in 11 patients, the most common combination being both right and left sided rectal tenderness. When patients with acute appendicitis and those with other causes of the pain were compared the odds ratio for right sided rectal tenderness was less than that for abdominal findings on clinical examination (table III). In the stepwise logistic regression for acute appendicitis if rebound tenderness was entered right sided rectal tenderness lost its significance. Of the 395 patients with acute appendicitis, 101 had neither rebound tenderness nor rectal tenderness to the right, 30 had right sided rectal tenderness without rebound tenderness, 160 had rebound tenderness without right sided rectal tenderness, and 104 had both. Of the 1028 patients examined, 116 had right sided rectal tenderness without rebound tenderness, of whom only 30 had acute appendicitis. Right sided rectal tenderness in the absence of rebound tenderness was therefore not significantly associated with acute appendicitis. Only two patients with acute appendicitis presented without any of the four signs in table III, and neither of these had rectal tenderness to the right. Thus no patients with acute appendicitis had rectal tenderness to the right in the absence of abdominal signs.

Table IV gives the factors that were of independent significance for acute appendicitis. Age was not an independent diagnostic factor, although in a univariate analysis acute appendicitis was significantly less common in older patients. The factor that was primarily responsible for explaining the relation with age was whether or not the patient had had previous surgery.

The only other association between the findings on rectal examination and diagnosis was that right sided rectal tenderness was less common in patients with renal colic than in patients with other conditions (odds ratio $0.22(95 \%$ confidence interval 0.06 to 0.61$)$; $\mathrm{p}<0.01$ ).

Rectal masses were palpated in six patients. Three of these were palpated on abdominal examination (two colonic cancers and one mass due to Crohn's disease), and the other three patients had acute appendicitis. No unsuspected disease was detected by rectal examination.

Analysis of subgroups suggested that rectal tenderness on the right side might be more strongly associated with acute appendicitis in older patients than younger patients (table V). In particular, a logistic regression confined to those aged over 30 showed a highly significant effect for right sided rectal tenderness when adjustment was made for sex. These older 
patients, however, also had more abdominal signs, and analysis after allowance for rebound tenderness showed that rectal tenderness on the right lost its significance. In women of childbearing age, among whom the rate of appendicectomy at which appendicitis is not found is high, the findings on rectal examination did not correlate significantly with the final diagnosis.

TABLE $\mathrm{v}-$ Relation between right sided rectal tenderness and acute appendicitis by age and sex

\begin{tabular}{|c|c|c|c|c|}
\hline \multirow{2}{*}{$\begin{array}{c}\text { Age } \\
\text { (years) }\end{array}$} & \multicolumn{2}{|c|}{$\begin{array}{l}\text { No }(\%) \text { of patients with } \\
\text { appendicitis if right sided } \\
\text { rectal tenderness: }\end{array}$} & \multirow{2}{*}{$\begin{array}{l}\text { Odds } \\
\text { ratio }\end{array}$} & \multirow{2}{*}{$\begin{array}{l}95 \% \text { Confidence } \\
\text { interval }\end{array}$} \\
\hline & Absent & Present & & \\
\hline \multicolumn{5}{|c|}{ Male patients } \\
\hline $\begin{array}{r}0- \\
15- \\
30- \\
\geqslant 45\end{array}$ & $\begin{array}{l}33(51) \\
80(61) \\
25(45) \\
25(31)\end{array}$ & $\begin{array}{r}23(64) \\
38(58) \\
9(75) \\
2(40)\end{array}$ & $\begin{array}{l}1 \cdot 72 \\
0 \cdot 88 \\
3 \cdot 72 \\
1 \cdot 49\end{array}$ & $\begin{array}{l}0.69 \text { to } 4.35 \\
0.46 \text { to } 1.69 \\
0.80 \text { to } 24.39 \\
0.12 \text { to } 13.83\end{array}$ \\
\hline \multicolumn{5}{|c|}{ Female patients } \\
\hline $\begin{array}{r}0- \\
15- \\
30- \\
\geqslant 45\end{array}$ & $\begin{array}{r}20(44) \\
38(22) \\
27(32) \\
9(13)\end{array}$ & $\begin{array}{r}25(51) \\
20(20) \\
11(55) \\
5(31)\end{array}$ & $\begin{array}{l}1 \cdot 30 \\
0 \cdot 86 \\
2 \cdot 58 \\
3 \cdot 13\end{array}$ & $\begin{array}{l}0.54 \text { to } 3.17 \\
0.44 \text { to } 1.64 \\
0.85 \text { to } 7.91 \\
0.68 \text { to } 12.82\end{array}$ \\
\hline
\end{tabular}

\section{Discussion}

In 1901 William Osler pointed out that in the early stages of acute appendicitis rectal examination rarely provides any valuable information. ${ }^{8}$ Despite this major textbooks of surgery indicate that it is of value. Most studies that have addressed this issue do not in fact show a correlation between the findings on rectal examination and the final diagnosis. ${ }^{3-5910}$ Only three reports have shown that rectal examination might be of diagnostic value in acute appendicitis. ${ }^{11-13}$ They, like the present study, showed that rectal tenderness on the right was more common in patients with acute appendicitis. What these three studies failed to do was to determine whether findings on rectal examination were independent of other clinical signs. Our data show that abdominal signs are better predictors of appendicitis and that if rebound tenderness is assessed rectal examination does not provide any further diagnostic information.

The wide range of rates of tenderness on rectal examination in patients with pain in the right lower quadrant is further evidence to suggest that rectal examination is of little value. These rates vary from $2.9 \%$ to $72 \%$ in patients with acute appendicitis and from $16 \%$ to $63 \%$ in patients with other causes of pain in the right lower quadrant. ${ }^{31213}$ The rate of acute appendicitis in patients with tenderness on rectal examination varies just as widely, from $3 \%$ to $72 \% .^{3}$

It could be argued that rectal examination might pick up other conditions, which would otherwise be missed. In the present study six patients had masses that were palpable on rectal examination. Of these, three were abscesses associated with acute appendicitis and the other three were palpable on abdominal examination. No patient had any unsuspected disease identified by routine rectal examination. In this group of over 1200 patients - roughly the total number of patients admitted as an emergency with pain in the right lower quadrant of the abdomen seen by a general surgeon during his or her years in training-routine rectal examination seemed to provide no information of diagnostic value, even in specific groups, such as elderly patients or women during their reproductive years.

The question that must be asked is, should rectal examination be performed in any patient with pain in the right lower quadrant of the abdomen? We believe that, in the light of this and other reports, it should not be part of the examination performed by a general practitioner before referral to hospital. In patients admitted to hospital with convincing abdominal signs of acute appendicitis it also seems unnecessary. In elderly patients it might theoretically pick up unsuspected disease, and on this basis it might be justified in patients over 50 years of age.

We thank Mr A A Gunn, who set up the computer system at Bangour General Hospital; the casualty officers and surgical registrars who completed the forms and entered data into the computer; Mrs Julie McLaren and Mrs Liz Wright, who entered the final diagnoses; and Mr Vic Mackinlay, who extracted data from the original computer file. Financial support for the computer analysis was provided by the Royal College of Surgeons of Edinburgh.

1 Cain A. Hamilton Bailey's demonstration of physical signs in clinical surgery. Bristol: Wright, 1986:297.

2 Condon RE. The small intestine: appendicitis. In: Sabiston DC Jr, ed. Textbook of surgery. 13th ed. Philadelphia: Saunders, 1986:971.

3 Bonnello JC, Abrams JS. The significance of a "positive" rectal examination in acute appendicitis. Dis Colon Rectum 1979;22:97-101.

4 Lewis FR, Holcroft JW, Boey J, et al. Appendicitis: a critical review of the diagnosis and treatment in 1000 cases. Arch Surg 1975;110:677-94.

5 Dickson AP, MacKinlay GA. Rectal examination and acute appendicitis. Arch Dis Child 1985;60:666-7.

6 Morris JA, Gardner MJ. Calculating confidence intervals for relative risks (odds ratios) and standardised ratios and rates. BMF 1988;296:1313-6.

7 Armitage P, Berry G. Statistical methods in medical research. 2nd ed. Oxford: Blackwell, 1987:386.

8 Osler W.'The principles and practices of medicine designed for the use of practitioners and students of medicine. New York: Appleton, 1901:525.

9 Teicher I, Landa B, Cohen M, Kabnick LS, Wise L. Scoring system to aid the diagnosis of appendicitis. Ann Surg 1983;198:753-9.

10 Nauta RJ, Magnant C. Observation versus operation for abdominal pain in the right lower quadrant: roles of clinical examination and the leukocyte count. Am f Surg 1986;15:746-8.

11 Smith PH. The diagnosis of appendicitis. Postgrad Med f 1965;41:2-5.

12 Kazarian KK, Roeder WF, Mersheimer WL. Decreasing mortality and Kazarian KK, Roeder WF, Mersheimer increasing morbidity from acute appendicitis. Am f Surg 1970;119:681-5.
ing

13 Magee RB, Stowell JM, MacDuffee RC. Appendicitis: an analysis of 2117 Magee RB, Stowell JM, MacDuffee RC. Appendicitis: an analysis of 2117
cases treated surgically in a community hospital during a period of 20 years. Pennsylvania Medicine 1967;70:47-50.

(Accepted 12 December 1990)
Correspondence to: Dr Chapman.

\section{Raised $\gamma$-glutamyltransferase activity and the need for liver biopsy}

\section{A Ireland, L Hartley, N Ryley, J O’D McGee, J M Trowell, R W Chapman}

Patients with a raised activity of $\gamma$-glutamyltransferase in the absence of other abnormal results on liver function tests are often referred to liver clinics. There is, however, no evidence that an isolated increase in $\gamma$-glutamyltransferase activity is associated with major liver pathology, and this study was designed to determine whether an increase in $\gamma$-glutamyltransferase alone was sufficient indication for performing a liver biopsy.

\section{Patients, methods, and results}

The case notes of 117 consecutive patients with suspected alcoholic liver disease who had a liver biopsy were reviewed and divided into three groups: increased $\gamma$-glutamyltransferase activity only (17 patients); increased aspartate aminotransferase activity with or without increased $\gamma$-glutamyltransferase (34 patients); and widespread abnormal results on liver function tests (66 patients). There was no difference in age among the three groups. Liver biopsy specimens were assessed blindly by one observer (NR), looking for steatosis, ballooning degeneration, megamitochondria, Mallory's 